\title{
La deuda con Palma
}

Pedro Díaz Ortiz

Instituto Ricardo Palma/Universidad Ricardo Palma, Lima - Perú tarmapap@yahoo.es

\section{Resumen:}

Desde la publicación de la Primera Serie de las Tradiciones peruanas de Ricardo Palma en 1872 hasta la actualidad, los escritores peruanos y latinoamericanos han reconocido a la tradición como un género literario creado por Ricardo Palma. Sin embargo, la Real Academia de la Lengua Española no ha admitido hasta ahora en su diccionario académico (DLE) la acepción de la tradición como género literario. En el presente artículo hacemos un recuento histórico de esta situación.

Palabras clave: tradición, deuda, género literario, esperpento, Ricardo Palma.

\section{Abstract:}

Since the publication of the first edition of Peruvian Traditions by Ricardo Palma in 1872 until our days, Latin American and Peruvian writers have recognized the Tradition as a literary gender created by Ricardo Palma. However, the Royal Spanish Academy has not yet accepted the definition of the word as a literary gender. In this article we present an historic review of this situation.

Keywords: tradition, debt, literary gender, esperpento, Ricardo Palma. 
Pedro Díaz Ortiz Escritor, traductor, editor. Doctor en Letras por la Universidad Nacional Mayor de San Marcos. Past-Decano de la Facultad de Humanidades y Lenguas Modernas de la Universidad Ricardo Palma, Ex Director de la Revista de la Facultad de Humanidades y Lenguas Modernas (URP). Director de la Serie "Letras Francesas". Ha publicado, entre otras obras, La estética teatral de ValleInclán; Un no rompido sueño; Edición crítica de la Primera Serie de Tradiciones Peruanas, de Ricardo Palma; Albert Camus. Teatro y sociedad, y Gaudeamus. Ha realizado diversas traducciones de poesía francesa, entre otras de Blaise Cendrars, Raymond Queneau, Georgette Vallejo y André Coyné. 
Con ocasión del próximo centenario de la muerte de Ricardo Palma (1919-2019), cabe una reflexión en torno a la ausencia de la acepción de tradición como "género literario creado por Ricardo Palma" a diferencia de lo que ocurre con el vocablo esperpento que sí aparece como "género literario creado por Ramón del Valle-Inclán”, tanto en la vigésima segunda como en la vigésima tercera versiones del Diccionario de la lengua española (DLE):

\section{Vigésima segunda edición del DLE}

\section{Tradición}

Tradición. (Del lat. traditĭo, -ōnis). f. transmisión de noticias, composiciones literarias, doctrinas, ritos, costumbres, etc., hecha de generación en generación. 2. Noticia de un hecho antiguo transmitida de este modo. 3. Doctrina, costumbre, etc., conservada en un pueblo por transmisión de padres a hijos. 4 . Elaboración literaria, en prosa o verso, de un suceso transmitido por tradición oral. 5. Der. Entrega a alguien de algo. Tradición de una cosa vendida. 6. Ecd. Conjunto de los textos, conservados o no, que a lo largo del tiempo han transmitido una determinada obra. La tradición del Libro de Buen Amor está formada por pocos manuscritos. (Negritas nuestras).

\section{Esperpento}

Esperpento. (De or. inc.). m. Hecho grotesco o desatinado. 2. Género literario creado por Ramón del Valle-Inclán, escritor español de la generación del 98, en el que se deforma la realidad, recargando sus rasgos grotescos, sometiendo a una elaboración muy personal el lenguaje coloquial y 
desgarrado. 3. coloq. Persona o cosa notable por su fealdad, desaliño o mala traza. (Negritas nuestras).

\section{Vigésima tercera edición del DLE}

\section{Tradición}

Tradición. (Del lat. traditĭo, -ōnis). l. f. Transmisión de noticias, composiciones literarias, doctrinas, ritos, costumbres, etc., hecha de generación en generación. 2. f. Noticia de un hecho antiguo transmitida por tradición. 3. f. Doctrina, costumbre, etc., conservada en un pueblo por transmisión de padres a hijos. 4. En varias religiones, cada una de las enseñanzas o doctrinas transmitidas oralmente o por escrito desde los tiempos antiguos, o el conjunto de ellas. 5. f. Conjunto de rasgos propios de unos géneros o unas formas literarias o artísticas que han perdurado a lo largo de los años. La tradición del bodegón en la pintura española. 6. f. Elaboración literaria de narraciones orales, fiestas o costumbres propias de un pueblo. Las tradiciones peruanas de Ricardo Palma. 7. f. Der. Entrega a alguien de algo. Tradición de una cosa vendida. 8. Ecd. Conjunto de los textos, conservados o no, que a lo largo del tiempo han transmitido una determinada obra. La tradición del Libro de Buen Amor está formada por pocos manuscritos. (Negritas nuestras).

\section{Esperpento}

Esperpento. (De or. inc). 1. m. Persona, cosa o situación grotescas o estrafalarias. Estás hecho un esperpento con esa chaqueta de tu padre. 2. m. Concepción literaria creada por Ramón M. ${ }^{a}$ del Valle-Inclán hacia 1920, en la que se deforma la realidad acentuando sus rasgos grotescos. 
3. m. Obra literaria acorde con el esperpento. (Negritas nuestras).

Como vemos, en ambos casos ha habido cambios, pero en lo que se refiere a la definición de tradición no se precisa que es un género literario creado por Ricardo Palma; y en lo que respecta a esperpento se ha cambiado la palabra género por concepción. Ausencia y cambio que no entendemos; en todo caso, quizá obedezca al humor de los académicos. Ya decía Rubén Darío: "De los académicos... líbranos, Señor".

\section{Algo de historia}

El año 1872, como se sabe, se publicó en un volumen la Primera Serie de las Tradiciones peruanas. Desde entonces el término tradición fue reconocido como un género literario creado por Ricardo Palma, tanto en el Perú como en el resto de los países americanos. De igual modo, el género mismo se expandió desde las tierras australes de Chile hasta México.

El 5 de julio de 1875, en carta dirigida al escritor argentino Juan María Gutiérrez, Palma le dice que en Santiago de Chile se está imprimiendo un volumen de Tradiciones chilenas, escritas por Enrique del Solar, y asimismo que Miguel Luis Amunátegui también va a coleccionar las que ha publicado en los diarios, a lo cual añade: "Como usted ve ha entrado fiebre de tradicionar lo que francamente es halagador para mí que he sido el iniciador de este género de escritos" (1949, tomo I, p. 19).

En la misma carta, Palma añade:

Un joven uruguayo don Francisco Escardó me escribe que va a publicar en Montevideo un libro de Tradiciones del Plata. Me ha enviado dos como muestra y tengo para mí que son mejores que las de Amunátegui. A pesar de su gran 
talento Amunátegui, en mi concepto ha escrito novelas y no tradiciones (1949, tomo I, p. 20)

Como vemos, en la carta que citamos, Palma advierte, en primer lugar, su influencia en la difusión del género de las tradiciones en Latinoamérica y, en segundo lugar, que es el iniciador (o creador) de las tradiciones como género literario ("un género de escritos", dice).

Siempre en torno a las tradiciones, en una carta a Francisco de Sosa de fecha 28 de noviembre de 1889, Palma dice:

He sido periodista en diversas épocas de mi vida. No sé si lo hice bien o mal. En literatura, he sido una especie de cajón de sastre. Cultivé todos los géneros, hasta que acerté con un filón, riquísimo para mí -el de las tradiciones-. El género cayó en gracia y me ha dado cierta popularidad (1949, tomo I, p. 225)

O mejor, mucha, a decir de Leopoldo Díaz: "No creo tributarle un elogio banal, al asegurarle, señor Palma, que en la República Argentina, en Chile y en el Uruguay, es Ud. el más estimado de los literatos americanos, y agregaré el más conocido" (en Palma, 1949, tomo II, p. 144).

La filiación de las tradiciones es palmista, y así lo reconocen los distintos tradicionistas hispanoamericanos que emulan a Palma desde México hasta Chile. Así, por ejemplo, en carta dirigida a Ricardo Palma el 18 de abril de 1891, el colombiano Rafael Pombo dice: "Ud. con sus inimitables Leyendas, ha creado ese género de literatura, ha inducido a muchos a novelizar nuestra historia, sin su estudio, sin su sal y primoroso desenfado de lenguaje" (Ibíd., p. 210). 
Y, por su parte, el tradicionista argentino Pastor Obligado, el 12 de agosto de 1897, le escribe a Palma:

Guardo colección de todas las ediciones de sus obras. Aunque escasas las mías, y siguiendo a distancia los pasos del Maestro, le he enviado la $1^{\mathrm{a}}, 2^{\mathrm{a}}$ y $3^{\mathrm{a}}$ serie de mis "Tradiciones de Buenos Aires". Próximo a coleccionar la cuarta, si tuviera Ud. tiempo, y voluntad, para escribir cuatro palabras de introducción, como de maestro a discípulo, aunque indigno, mucho le agradecería, siendo Ud. el creador del género vendrían no sólo a exornar la portada del último tomo, sino como buen consejo (anticipadamente aceptado) del precursor en el mismo camino (Ibíd., p. 323).

Este reconocimiento decimonónico a Ricardo Palma como el creador del género literario de las tradiciones continuó en el siglo XX en la cala de los más reputados estudiosos de la obra palmista como Raúl Porras Barrenechea que dice: "La tradición creada por Palma es un género literario propio e inconfundible que no se amolda ni cabe en los géneros conocidos. Es un producto genuino, limeño y propio. No es historia, novela, ni cuento, ni leyenda romántica" (en Palma, 1945, p. XLIV).

Estuardo Núñez, por su parte, afirma:

La Tradición resultó así la solución en la coyuntura de superar formas literarias de escasa proyección para dar paso a una nueva forma, o género, con la cual obtuvo una doble finalidad prospectiva, pues suponía de un lado superar al localismo centralista y abrir de otro lado, democráticamente, las posibilidades de hacer literatura de raíz nacional auténtica y no imitativa. Estas primeras decisiones de Palma están implicadas en torno a la superación del costumbrismo, se dirigía al fomento de una nueva forma o género literario que agregase al relato real escueto una 
trama ficticia. Esta incorporación de lo imaginario en lo real daba como resultado el surgimiento de la llamada Tradición, género literario de típica factura peruana y de proyección hispanoamericana (1999, p. 18).

Entre 1872 y 1910, Ricardo Palma publicó sus diez series de Tradiciones peruanas. El año 1920, con la publicación de Luces de Bohemia, y en 1921, de Los cuernos de Don Friolera, Ramón del Valle-Inclán definió la estética de su gran creación teatral: el esperpento, término que fue incorporado por el DLE como género literario creado por Valle-Inclán, mas hasta ahora no se ha procedido así con el vocablo tradición que, como hemos señalado anteriormente, debería incorporarse también como género literario creado por Ricardo Palma.

¿Por qué entonces la Real Academia Española no consigna en el DLE el término tradición como género literario creado por Palma? Más aún si se sabe que Ricardo Palma fue el promotor y fundador de la Academia Peruana de la Lengua, de un lado; y del otro, uno de los primeros y más activos defensores de la incorporación de americanismos y peruanismos al DLE, tanto en sus gestiones directas en España (Díaz Plaja, 1983, pp. 4351) como en sus obras Neologismos y Americanismos y Papeletas Lexicográficas. Dos mil setecientas voces que hacen falta en el diccionario.

El mismo Miguel de Unamuno reconoce esta labor en una carta dirigida a Palma con fecha 29 de octubre de 1903, donde dice:

Mi estimado señor Palma: conocía a usted por diversos escritos suyos -las Tradiciones Peruanas, en especial- y lo estimaba en mucho. Vea, pues, si me habrá sido bienvenida su obra de Papeletas lexicográficas. La anterrotula usted así: "dos mil setecientas voces que hacen falta en el Diccionario...

iSi no fueran más!" (1949, tomo II, p. 393). 
En otra carta -esta vez de fecha 18 de abril de 1904-, Unamuno refiriéndose a la testarudez de la Academia de la Lengua Española que no aceptaba los términos propuestos por Palma, enfatiza:

Lo que me dice de la testarudez académica es el evangelio puro. Mas aquí cada vez nos hacemos menos caso de la tal Academia y el lenguaje se ensancha y flexibiliza sin contar con ella. Su papel debe ser aceptar lo que aceptó el pueblo. Pero, por desgracia, lejos de ser una corporación conservadora lo es reaccionaria. Santo y bueno que no se precipite a admitir cualquier novedad, pero es torpeza, no poner el sello a lo que sin él corre. No quieren comprender que oro de ley sin acuñar vale más que oro malo acuñado. No entienden el liberalismo lingüístico a derechas, sino que plantan aduanas y derechos arancelarios y no quieren poner el marchamo a esto o aquello. (1949, tomo II, p. 396)

Ahora bien, frente a la no inclusión del vocablo tradición como género literario creado por Palma, ¿cómo actuaron las Academias de la Lengua de los países latinoamericanos y, especialmente, la Academia Peruana de la Lengua?

En el Boletín de la Academia Peruana de la Lengua $\mathrm{N}^{\circ} 18$, año de 1983, en la nota El Perú en la Asociación de Academias de la Lengua (informe presentado a la Academia Peruana de la Lengua por el Secretario Perpetuo de la Corporación, Don Estuardo Núñez), se señala:

Una muestra de especial aprecio para con nuestra Academia merece ser destacada. Al plantearse por el suscrito que se discutiera con preferencia, alterando el orden establecido, el agregado de la acepción 5) de la voz "tradición", la Comisión de Diccionarios estuvo acorde en aceptarla con el siguiente texto: “Tradición ... 5. Narración breve con elementos de ficción, historia y costumbrismo; género iniciado en América por Ricardo Palma. 
Este acuerdo de la Comisión de Diccionarios, que reafirma lo planteado en la Comisión Permanente por nosotros, constituye un homenaje significativo en el año del sesquicentenario del insigne tradicionista. El acuerdo pasará de inmediato al Plenario para su ratificación e inclusión en la próxima edición del Diccionario matriz (p. 219)

Cuatro años después, en el Suplemento Dominical de El Comercio, de fecha 30 de agosto de 1987, en el artículo "Destino de las Academias", Estuardo Núñez dice que en 1951 se convocó en México al primer Congreso de Academias al que siguieron otros hasta el que tuvo lugar en Lima en 1980. De estos congresos salió un acuerdo de crear la Comisión Permanente de la Asociación de Academias, encargada de velar por el mantenimiento de la unidad, el estudio y la defensa del idioma. En esta Comisión que funciona anexa a la Corporación madrileña, sigue diciendo Núñez: Están representadas en forma rotativa las diversas academias americanas, que así sustentan sus aportaciones lexicográficas con oportunidad y eficacia. Un ejemplo objetivo de esta práctica es la reciente aprobación de la quinta acepción del vocablo ‘tradición' como ‘narración breve, con elementos de ficción, historia y costumbrismo; género iniciado en América por Ricardo Palma'. Este texto figurará así en la vigésima primera edición del Diccionario de la Academia (p. 7).

Sin embargo, tanto en la vigésima primera como en la vigésima segunda edición del DLE, la Real Academia Española no consideró la propuesta de Estuardo Núñez; y, en la vigésima tercera solo incluyó esta nueva acepción del término tradición: “6. f. Elaboración literaria de narraciones orales, fiestas o costumbres propias de un pueblo. Las tradiciones peruanas de Ricardo Palma" (DLE, 2014), que tampoco considera a la tradición como género literario creado por Ricardo Palma. 
Cabe entonces preguntarse, como decía Unamuno, ¿si sigue siendo la testarudez académica el evangelio puro?, ¿y los académicos no entienden el liberalismo lingüístico a derechas, sino que plantean aduanas y derechos arancelarios y no quieren poner el marchamo a esto o aquello?

La Real Academia Española está, pues, -en opinión nuestra- en deuda con Ricardo Palma, y para que haya por lo menos un símil con lo establecido por la Real Academia Española con respecto a la definición de esperpento, sugerimos que el Instituto Ricardo Palma, con el apoyo de algunos de sus miembros que también forman parte de la Academia Peruana de la Lengua, reitere la propuesta de Estuardo Núñez ("Tradición... 5. f. Narración breve con elementos de ficción, historia y costumbrismo; género iniciado en América por Ricardo Palma") para que esta sea incorporada como tal al DLE en reconocimiento a la obra del creador de las Tradiciones peruanas.

\section{Bibliografía}

Díaz Plaja, G. (1983). "Ricardo Palma y la Real Academia Española”. Boletín de la Academia Peruana de la Lengua. № 18, Lima, pp. 48-49.

Núñez, E. (1983). "Informe sobre el Perú en la Asociación de Academias de la Lengua". Anexo del Boletín de la Academia Peruana de la Lengua $\mathrm{N}^{\circ} 18$, p. 217 , Lima.

(1987). "Destino de las Academias". El Comercio, Suplemento Dominical, No 35, 30 de agosto, 1987, Lima.

(1999). "Ricardo Palma en el tiempo y en el espacio". Aula Palma. Discurso de Incorporación. Aula Palma. Lima: Universidad Ricardo Palma. 
Palma, R. (1945). Tradiciones peruanas. Selección y Reseña de la Historia Cultural del Perú por Raúl Porras Barrenechea. Colección Panamericana, Buenos Aires: Ed. W. M. Jackson, Inc.

(1949). Epistolario. Lima: Ed. Cultura Antártica, Tomos I y II.

Real Academia Española. (2001). Diccionario de lengua española. Vigésima segunda edición. Madrid: S.L.U. Espasa Libros.

. (2014). Diccionario de lengua española. Vigésima tercera edición. Madrid: S.L.U. Espasa Libros.

Recibido el 16 de octubre del 2018 Aceptado el 2 de noviembre del 2018 